Provided for non-commercial research and education use. Not for reproduction, distribution or commercial use.

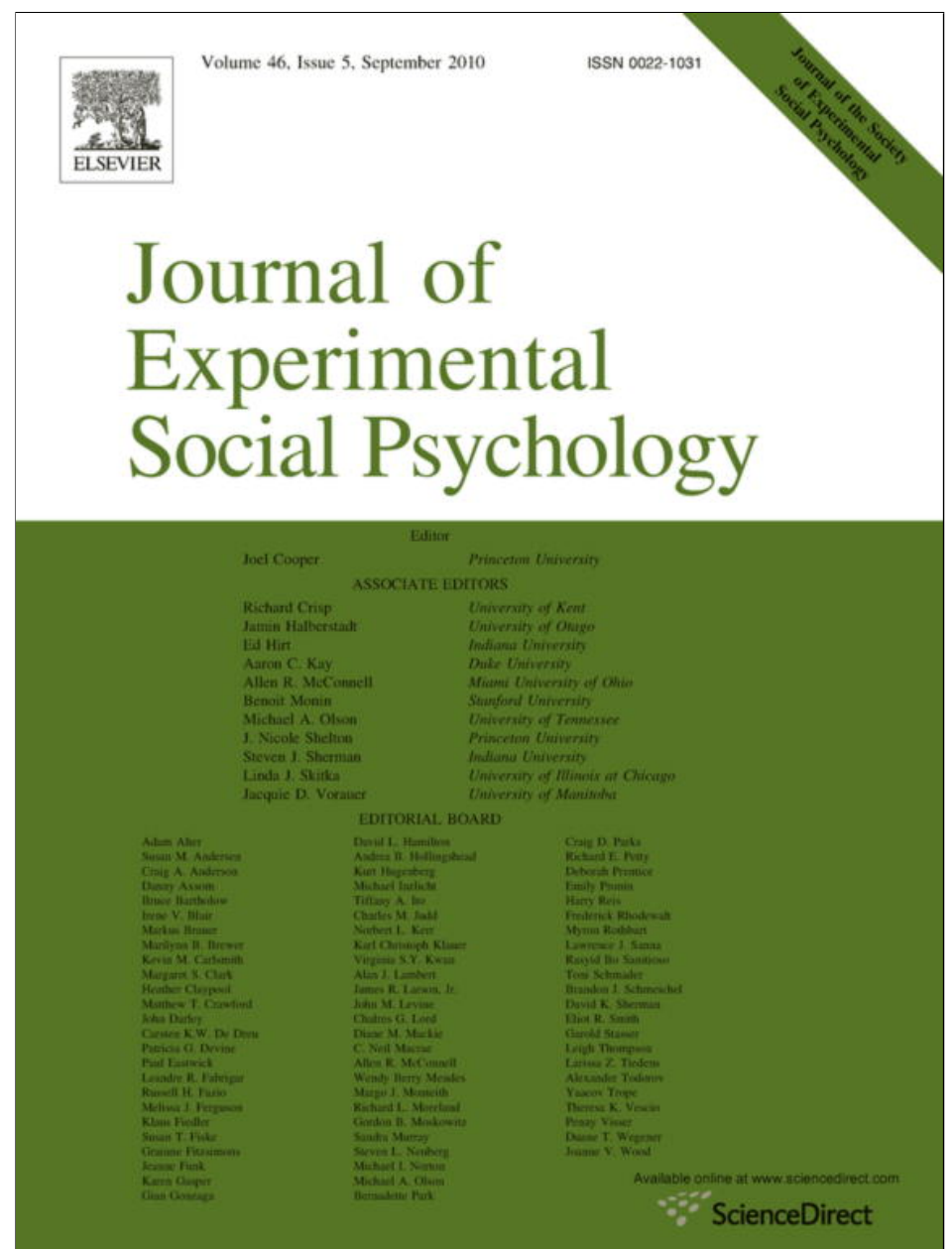

This article appeared in a journal published by Elsevier. The attached copy is furnished to the author for internal non-commercial research and education use, including for instruction at the authors institution and sharing with colleagues.

Other uses, including reproduction and distribution, or selling or licensing copies, or posting to personal, institutional or third party websites are prohibited.

In most cases authors are permitted to post their version of the article (e.g. in Word or Tex form) to their personal website or institutional repository. Authors requiring further information regarding Elsevier's archiving and manuscript policies are encouraged to visit:

http://www.elsevier.com/copyright 
FlashReports

\title{
Incentivizing education: Seeing schoolwork as an investment, not a chore
}

\author{
Mesmin Destin, Daphna Oyserman* \\ University of Michigan, Ann Arbor, MI, United States
}

\section{A R T I C L E I N F O}

\section{Article history:}

Received 25 September 2009

Revised 16 February 2010

Available online 18 April 2010

\section{Keywords:}

Motivation

Academic achievement

Socioeconomic status

Future identity

Possible selves

Race

Social cognition

\begin{abstract}
A B S T R A C T
Most American children expect to attend college but because they do not necessarily spend much time on schoolwork, they may fail to reach their imagined "college-bound" future self. The proposed identitybased motivation model helps explain why this gap occurs: Imagined "college-bound" identities cue school-focused behavior if they are salient and feel relevant to current choice options, not otherwise. Two studies with predominantly low-income and African American middle school students support this prediction. Almost all of the students expect to attend college, but only half describe education-dependent (e.g., law, medicine) adult identities. Having education-dependent rather than education-independent adult identities (e.g., sports, entertainment) predicts better grades over time, controlling for prior grade point average (Study 1). To demonstrate causality, salience of education-dependent vs. education-independent adult identities was experimentally manipulated. Children who considered education-dependent adult identities (vs. education-independent ones) were eight times more likely to complete a take-home extra-credit assignment (Study 2).
\end{abstract}

(c) 2010 Elsevier Inc. All rights reserved.

\section{Introduction}

Sports, video games, or homework? A variety of choices compete for children's time and attention. Children are unlikely to succeed academically if schoolwork consistently fails to be chosen, yet they may under invest in schoolwork even while desiring school success. For example, when asked how far they expect to go in school, most children in their last year of middle school report expecting to attend college, but this expectation does not predict the coursework they plan for the coming year (Trusty, 2000). These results, from national survey data, hold equally for low-income and minority students (Mello, 2009). Indeed, African American and Latino low-income children value education (e.g., Harris, 2008; Steinberg, Dornbusch, \& Brown, 1992) and expect to attend college (Mello, 2009) yet do not necessarily expend sufficient school-focused effort to attain such "college-bound" imagined future selves, on average investing less time in schoolwork (Steinberg et al., 1992) and being more likely to fail (Orfield, 2004).

To understand why this gap occurs we turned to identity-based motivation theory, which postulates first that people prefer to act in ways that feel identity congruent and second that the identityto-choice linkage is often unclear (Oyserman, 2007, 2009; Oyserman, Fryberg, \& Yoder, 2007). Identities feel stable but they are highly sensitive to contextual cues. Which identities come to mind,

\footnotetext{
* Corresponding author. Address: 426 Thompson Ave., The Institute for Socia Research, The University of Michigan, Ann Arbor, MI 48106-1248, United States. Fax: +1 7346473652

E-mail address: daphna.oyserman@umich.edu (D. Oyserman).
}

what these identities mean and which behaviors feel congruent with them are highly influenced by situational cues. Thus, an identity is more likely to matter for behavioral choices when it is salient and meaningful in the moment (Oyserman, Bybee, \& Terry, 2006).

With regard to the gap between college-bound identities and school-focused behavioral choices, the identity-based motivation model yields the following predictions. First, having a collegebound imagined future does not necessarily predict behavior because this possible future identity may not be salient when choices are made. Second, children are more likely to expend effort on school if this effort feels like an investment toward attaining an education-dependent future identity, and not like a future identity-irrelevant chore. Because adolescent future identities are career and wage-earner focused (Erikson, 1963), when these future identities feel, consciously or nonconsciously, education-dependent they are more likely to incentivize effort in school. In contrast, future identities perceived as education-independent will not cue school-focused choices.

For several reasons, having a chronically or situationally salient education-dependent future identity is unlikely for low-income and minority children. First, these children are likely to grow up in neighborhoods with higher than average unemployment and poverty (Bureau of Labor Statistics, 2009). Such neighborhoods are often segregated, providing very limited exposure to adults who are college graduates (Adelman \& Gocker, 2007; Krivo, Peterson, Rizzo, \& Reynolds, 1998), making salient instead the possible adult identity of becoming a paid worker who can earn a living and support a family (Bowlby, Evans, \& Mohammad, 
1998; Mickelson, 1990; Pahl, 1988). Second, these neighborhoods are "media saturated", providing vivid models of adult identities that seem education-independent, such as professional athletes and entertainers (Roberts, 2000). Low-income minority children watch more television than higher income white children (Christiansen, 1979) and report drawing future identities from television personalities and the roles they play (Boon \& Lomore, 2001; King \& Multon, 1996). As a consequence, their college-bound possible identities are unlikely to be contextually cued and cued adult identities are unlikely to feel education-dependent. Indeed, there is some evidence that for minority students, school focus decreases when primed with education-independent rather than educationdependent media icons (Fryberg, Markus, Oyserman, \& Stone, 2008). Following the identity-based motivation model, having a college-bound possible identity is unlikely to matter if it is never salient and more chronically salient adult identities, including careers, will only evoke increased investment in school if they are conceptualized as education-dependent (see Figs. 1 and 2).

Two studies demonstrate the effect of salient education-dependent vs. education-independent adult possible identities on current education-focused choices. Replicating survey results, Study 1 demonstrates that low-income children expect to attend college. Moving beyond prior research, Study 1 then demonstrates that when education-dependent adult future identities are chronically salient, children's school outcomes improve. Study 2 uses a subtle experimental manipulation to demonstrate the causal impact of salient adult future identities. Children led to focus on a future identity that feels dependent on education should engage in school more than children led to focus on a future identity that feels independent of education.

\section{Study 1}

We hypothesized that children would invest more effort in school and attain better grades over time if education-dependent rather than education-independent adult identities were salient. We operationalized salience as education-dependent (vs. education-independent) descriptions of adult possible identities, testing our hypothesis with two outcome variables - time spent on homework and end-of-term grade point average, controlling for prior grades.

\section{Sample and procedure}

Eighth graders from three Detroit middle schools $(n=266,72 \%$ African American, 17\% Latino, 11\% White) serving high poverty (54.1\% of households below poverty line; two-thirds receiving free/reduced price school lunches) and high unemployment neighborhoods (43.4\% of adults were employed, US Census Bureau,

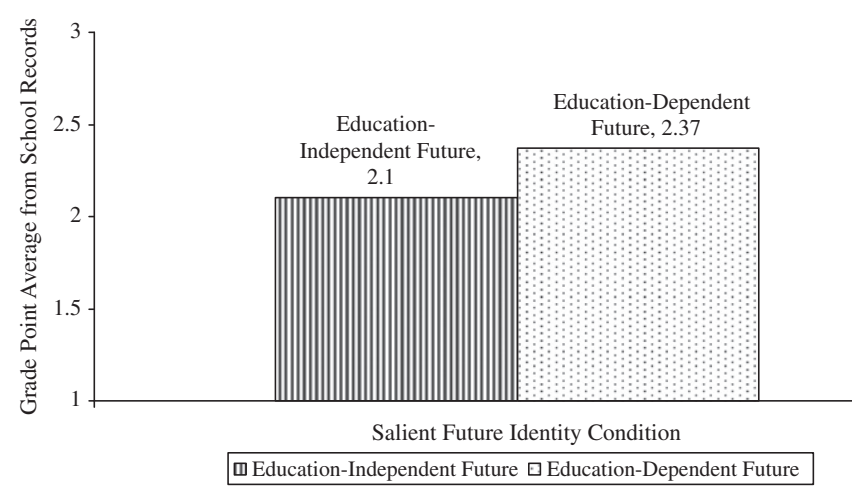

Fig. 1. Association of salient future identity with academic achievement.

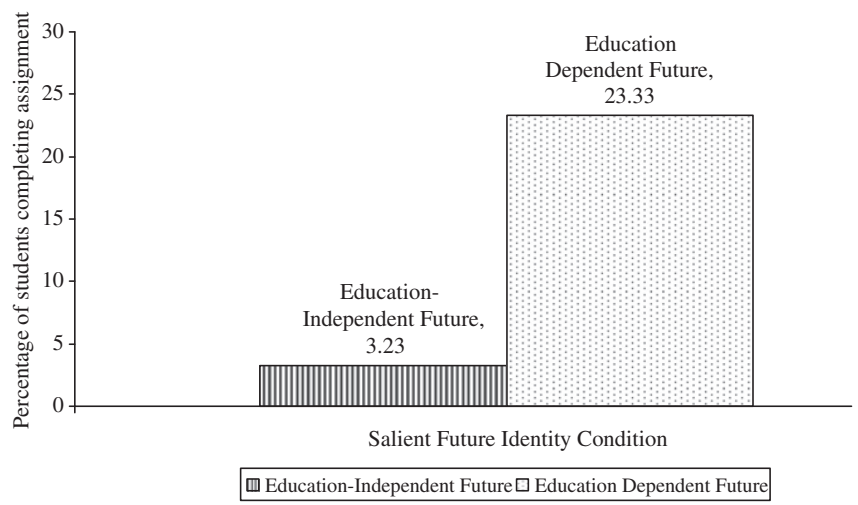

Fig. 2. Effect of salient future identity manipulation on effort in school.

2000) participated as part of a larger study. Students encountered the following prompt: "The next questions are about the job you see yourself having as an adult. Think about yourself as an adult, what job do you think you'll have (if more than one, you can answer for the job you feel you will be most likely to have). What will you be doing in 10 years?" Responses were content coded to distinguish education-dependent adult identities that mentioned school (e.g., "Going to college and starting a new career as an engineer") from education-independent adult identities that did not mention school (e.g., "I will be playing professional soccer or football").

Children indicated weekly homework time (8-point response scale: $0=0 \mathrm{~h}$ a week, to $7=$ more than $10 \mathrm{~h}$ a week, $M=3.91$, $S D=1.91,4=2-3 \mathrm{~h}$ a week of homework) and how far they expected to go to in school $(1=$ attend high school, to $6=$ attend 2 year or community college, $7=$ attend 4 -year college $8=$ attend graduate or professional school, $M d=8$, Mode $=8, M=7.00$, $S D=2.00$ ). Baseline and end-of-term grade point average (GPA) were obtained. Data were collected at the start of the academic year. Therefore at baseline school records could not be used. The baseline measure ("What grades do you usually get") was self-reported on a 9 -point response $(0=$ mostly F's to $8=$ mostly A's, $M=5.63, S D=1.53)$, where $6=$ mostly B's. End-of-term GPA was obtained from school records ( $0-4$ point scale, $M=2.22$, $S D=.78$, where 2.0 is a C).

\section{Results and discussion}

Replicating national survey responses, almost all children had very high educational expectations. Nine of 10 (88.8\%) expected to attend at least a two-year college. Very few $(8.8 \%)$ expected to attain a high school degree or less. However, only half of children (46\%) expected an education-dependent adult identity (54\% expected an education-independent adult identity) and this difference mattered. Children invested more time on homework and got better grades over time when their adult identity was education-dependent rather than education-independent. Though statistically marginally associated with planned effort (educationdependent $M=4.11, \quad S D=1.81 \quad$ vs. education-independent $M=3.73, S D=1.98), F(1,264)=2.74, p=.10$; the effect of education-dependent future identity $(M=2.37, S D=.73$, vs. educationindependent $M=2.10, S D=.80$ ) on grades was statistically significant $(F(1,264)=7.83, p<.01)$ even when controlling for baseline grades $(F(1,263)=5.19, p<.05)$. Children who envisioned an education-dependent adult identity were more likely to invest current effort in schoolwork than those who did not and these efforts paid off in better grades.

Study 1's strengths were in yielding important findings about the spontaneous salience of education-dependent adult identities 
and the temporal effect of these identities on school grades as obtained from school records. However, Study 1 was limited in a number of ways. First the measure of effort was self-reported. Second, we measured rather than manipulated the salience of education-dependent adult identities. To establish causality, in Study 2 our goal was to experimentally manipulate salience, conceptually replicate behavioral self-report results, and demonstrate an effect on actual behavior in natural context.

\section{Study 2}

We hypothesized that children would invest more effort in school if education-dependent, not education-independent, adult identities were salient. We focused on a central component of identity in adolescence, future wage-earning careers (Erikson, 1963). We experimentally manipulated whether these futures would feel education-dependent or education-independent and assessed effects on both planned effort (time spent on homework) and actual effort (completion of an extra-credit assignment) controlling for prior grades.

\section{Sample and procedure}

A cohort of seventh-grade children ( $n=295$, African American $57 \%$, White $29 \%$, Biracial/Other/No response $12 \%$, Latino $2 \%$ ) in a Detroit-area middle school (61\% eligible for free/reduced lunch) participated in their science classrooms (two science classrooms and five class periods). Science classrooms were not achievement tracked and all children participated on the same day. Each teacher agreed to assign students an extra-credit assignment relevant to current class material (unrelated to the experiment) at the end of the class period.

Teacher and condition were not confounded - children were randomly assigned to condition (education-dependent, educationindependent) by class period across both classrooms. In each class period, the teacher briefly introduced the experimenter as a visitor from a local university, distributing career-related information. Students were also told that they would be asked complete a short time use questionnaire as part of a separate general survey that would not ask students for their name or affect their grade. Teachers then left the classroom and remained blind to condition and hypotheses.

The career-related information sheet provided real and relevant information about adult earnings presented as graphs. Children saw one of two graphs. The education-dependent condition graph showed a step-wise increase in median earnings by level of education (no high school degree, high school graduate, 4-year college degree, beyond 4-year college - medicine, business, law, $\mathrm{PhD}$ ) in Michigan, the state in which children resided (US Census Bureau, 2006). The education-independent condition graph showed median earnings in Michigan and the very high earnings of top actors, athletes, and musicians (Forbes Magazine., 2008). We used these careers both because in Study 1 these were common among education-independent adult identity descriptions and because prior research suggests that these are salient adult career identities among low-income and minority children (Guiffrida, 2009). Thus, the education-dependent condition drew explicit attention to the connection between education and adult wage-earning identities, while the education-independent condition made no mention of education. In addition to passing out a graph to each child, the experimenter read the content of the graph out loud verbatim (without comment or further description) to control reading comprehension differences. Then students received a survey of everyday behaviors to fill out on their own. At the end of the survey they indicated gender and student number. Then the experimenter thanked the class and left, ostensibly ending the study.

Planned effort was operationalized as two critical items (homework and study time, $M=1.50, S D=1.43, \alpha=.81$ ) embedded in fillers (watching TV, listening to music, playing video games, playing sports, using the computer) in the survey of everyday behaviors (to avoid demand effects). Actual effort was operationalized as whether children handed in their extra-credit assignment the next day, at which time, all classes were debriefed and provided with information focusing on the benefits of a college education.

To assess actual effort uncontaminated by condition, teachers were simply asked to hand out course-relevant extra-credit, remaining blind to condition and hypotheses. We did not set what the extra-credit would be and assumed it would be the same assignment across class periods. However, due to budget constraints, teachers simply used copies of worksheets they already had on hand so that class periods received different worksheets. One teacher handed different worksheets for all five class periods and the other teacher handed out different worksheets for three class periods then ran out of worksheets and assigned a written topic with instructions to be copied from the board, conflating assignment and condition in all but these latter two class periods $(N=61)$, one in the education-dependent and the other in the education-independent condition.

\section{Results and discussion}

When adult identities were presented as education-dependent, children invested more effort in school (planned effort $M=1.67$, $S D=1.60$ vs. $M=1.24, S D=1.08, F(1293)=6.34, p<.05$, actual effort logistic regression $\beta=2.25, S E=1.13, p<.05)$. Actual effort increased almost eightfold ( $23.33 \%$ vs. $3.23 \%)$. The positive effect of salient education-dependent futures remained even after we added controls for teacher (for planned effort), prior GPA, and gender (planned effort $F(1221)=4.72, p<.05$, actual effort $\beta=2.21$, $S E=1.10, p<.05)^{1}$

\section{General discussion}

Children commonly imagine college-bound future identities but these identities do not necessarily translate into investment in schoolwork (e.g., Harris, 2008; Mello, 2009; Trusty, 2000). In two studies, we predicted and found that effort in school increased when salient adult identities felt education-dependent (not education-independent). Study 1 demonstrated that almost all children expected to attend college but only about half had adult wageearning identities that were education-dependent. Moreover, children planned to spend more time on schoolwork and in fact attained better grade point averages (controlling for baseline grades) when their adult wage-earning identities were education-dependent, not education-independent. To test the causal effect of salient education-dependent wage-earning identities in Study 2, we manipulated which identity was salient. In the education-dependent condition wage-earning increased with education, in the education-independent condition wage-earning was not explicitly education-linked. As predicted, when the future felt education-dependent, children planned to study more and most impressively, in this condition, eight times as many children went home and actually did an extra-credit assignment.

Our studies were conducted in field settings and assessed actual school-related behaviors. Their strength is the combination of

\footnotetext{
Priming focused children's attention on schoolwork, not away from any particular alternative activity (item-level $p s>0.2$ ). Some of these alternative activities varied by gender but gender had no effect (main or interaction) on planned or actual school effort.
} 
ecological validity (Study 1 ) and internal validity (Study 2). Together, our findings argue for the powerful effect of considering the distal future (adult wage-earning identity) as linked to the proximal future (youth student identity) and for the ability of a small manipulation to make this link salient even in the face of many competing influences. Of course any set of studies also carries limitations and future research may be necessary to determine how students understood the material and explicitly quantify the effect of the manipulation on student identities. Also, while assignment to condition by classroom helped the experimenter gain the full attention of a class of students and results were robust to control for prior academic attainment, operationalized as GPA, assignment at the individual level (e.g., through writing or individualized presentation) can help determine how children process this information and demonstrate further stability of this effect.

In addition to demonstrating the need to prime educationdependent future identities, our results also inform an ongoing debate regarding the academic value of athletic participation for low-income and minority youth. Despite apparent benefits for academic achievement and outcomes for more privileged youth, national survey data do not yield positive effects of athletic participation for urban and minority youth (Eitle, 2005; Fauth, Roth, \& Brooks-Gunn, 2007; Melnick, Sabo, \& Vanfossen, 1992b; Sabo, Melnick, \& Vanfossen, 1993) or female and rural Latino youth (Melnick, Sabo, \& Vanfossen, 1992a; Troutman \& Dufur, 2007). Our results are congruent with these analyses, implying that for lowincome and minority children, sports do not necessarily cue school-focused effort. Future studies are needed to understand when sports cue education-dependent vs. education-independent adult identities.

Studies 1 and 2, together with results of a randomized clinical trial (Oyserman et al., 2006), demonstrate the power of subtle cues in framing whether school-focused effort feels identity congruent or not and highlight the power of small interventions to influence low-income and minority children's school-focused future identities and subsequently their grades over time. Children are more likely to engage in current school-focused effort when adult wage-earning identities feel education-dependent, linking proximal and distal future identities to current effort. Failing to see connections between adult identities and current action puts children at risk of low school-focused effort. Waiting until low-income and minority children are in high school to make connections to college-bound programs increases the chance that they will already be too far behind to make a college-bound future viable.

\section{Acknowledgments}

Funding for this study was provided by the Michigan Prevention Research Training Grant (NIH Grant number T32 MH63057), by an NIH grant to Daphna Oyserman (NIH Grant number R01 MH58299) and by an NSF Graduate Research Fellowship.

\section{References}

Adelman, R. M., \& Gocker, J. C. (2007). Racial residential segregation in urban America. Sociology Compass, 1(1), 404-423.

Boon, S. D., \& Lomore, C. D. (2001). Admirer-celebrity relationships among young adults: Explaining perceptions of celebrity influence on identity. Human Communication Research, 27(3), 432-465.
Bowlby, S., Evans, S. L., \& Mohammad, R. (1998). Becoming a paid worker: Images and identity. In T. Skelton \& G. Valentine (Eds.), Cool places: Geographies of youth cultures (pp. 229-248). New York: Routledge.

Bureau of Labor Statistics (2009). Employment status of the civilian noninstitutional population by age, sex, and race. <http://www.bls.gov/cps/cpsaat3.pdf>.

Christiansen, J. B. (1979). Television role models and adolescent occupational goals. Human Communication Research, 5(4), 335-337.

Eitle, T. M. (2005). Do gender and race matter? Explaining the relationship between sports participation and achievement. Sociological Spectrum, 25(2), 177-195.

Erikson, E. H. (1963). Childhood and Society. New York: W. W. Norton \& Company.

Fauth, R. C., Roth, J. L., \& Brooks-Gunn, J. (2007). Does the neighborhood context alter the link between youth's after-school time activities and developmental outcomes? A multilevel analysis. Developmental Psychology, 43(3), 760-777.

Forbes Magazine. (2008). The Celebrity 100. <http://www.forbes.com/2008/06/11/ most-powerful-celebrities-lists-celebrities08-> Retrieved March 2009.

Fryberg, S. A., Markus, H. R., Oyserman, D., \& Stone, J. M. (2008). Of warrior chiefs and Indian princesses: The psychological consequences of American Indian mascots. Basic and Applied Social Psychology, 30, 208-218.

Guiffrida, D. (2009). Theories of human development that enhance an understanding of the college transition process. Teacher's College Record, 111, 2419-2443.

Harris, A. L. (2008). Optimism in the face of despair: Black-white differences in beliefs about school as a means for upward social mobility. Social Science Quarterly, 89(3), 608-630.

King, M. M., \& Multon, K. D. (1996). The effects of television role models on the career aspirations of African American junior high school students. Journal of Career Development, 23(2), 111-125.

Krivo, L. J., Peterson, R. D., Rizzo, H., \& Reynolds, J. R. (1998). Race, segregation, and the concentration of disadvantage: 1980-1990. Social Problems, 45(1), 61-80.

Mello, Z. R. (2009). Racial/ethnic group and socioeconomic status variation in educational and occupational expectations from adolescence to adulthood. Journal of Applied Developmental Psychology, 30(4), 494-504.

Melnick, M. J., Sabo, D. F., \& Vanfossen, B. (1992a). Effects of interscholastic athletic participation on the social, educational and career mobility of hispanic girls and boys. International Review for the Sociology of Sport, 27(1), 57-74.

Melnick, M. J., Sabo, D. F., \& Vanfossen, B. (1992b). Educational effects of interscholastic athletic participation on African-American and Hispanic youth. Adolescence, 27(106), 295-308.

Mickelson, R. A. (1990). The attitude-achievement paradox among black adolescents. Sociology of Education, 63(1), 44-61.

Orfield, G. (2004). Dropouts in America: Confronting the graduation rate crisis behind by the graduation rate crisis. Cambridge: Harvard Education Press.

Oyserman, D. (2007). Social identity and self-regulation. In A. W. Kruglanski \& E. T. Higgins (Eds.), Social psychology: Handbook of basic principles (2nd ed., pp. 432-453). New York: Guilford Press.

Oyserman, D. (2009). Identity-based motivation: Implications for action-readiness, procedural-readiness, and consumer behavior. Journal of Consumer Psychology, 19(3), 250-260.

Oyserman, D., Bybee, D., \& Terry, K. (2006). Possible selves and academic outcomes: How and when possible selves impel action. Journal of Personality and Social Psychology, 91(1), 188-204.

Oyserman, D., Fryberg, S. A., \& Yoder, N. (2007). Identity-based motivation and health. Journal of Personality and Social Psychology, 93(6), 1011-1027.

Pahl, R. E. (1988). On work: Historical, comparative, and theoretical approaches. New York: Basil Blackwell.

Roberts, D. F. (2000). Media and youth: Access, exposure, and privatization. Journal of Adolescent Health, 27S(2), 8-14.

Sabo, D., Melnick, M. J., \& Vanfossen, B. E. (1993). High school athletic participation and postsecondary educational and occupational mobility: A focus on race and gender. Sociology of Sport Journal, 10(1), 44-56.

Steinberg, L., Dornbusch, S. M., \& Brown, B. B. (1992). Ethnic differences in adolescent achievement: An ecological perspective. American Psychologist, 47(6), 723-729.

Troutman, K. P., \& Dufur, M. J. (2007). From high school jocks to college grads: Assessing the long-term effects of high school sport participation on females' educational attainment. Youth \& Society, 38(4), 443-462.

Trusty, J. (2000). High educational expectations and low achievement: Stability of educational goals across adolescence. Journal of Educational Research, 93(6), 356-395.

US Census Bureau (2000). Census 2000. <www.census.gov> Retrieved April 2006.

US Census Bureau (2006). Current population survey, annual social and economic supplement. <www.census.gov> Retrieved January 2008. 